\title{
Vínculo na balança: a relação mãe-filho influenciando o tratamento da obesidade infantil
}

\author{
Bond on balance: the mother-child relation influencing the childhood obesity treatment
}

\author{
Tatiane Britto da Silveiraa , Camila Irigonhé Ramos ${ }^{b}$, Priscila Wittemberg Azevedoc \\ a Psicóloga. Mestre em Ciências da Saúde, Doutoranda em Ciências da Saúde pela Universidade Federal do Rio Grande (FURG). Especialista em Saúde da Família e \\ Especialista em Atenção à Saúde da Criança. \\ b Nutricionista. Mestre em Nutrição e Alimentos. Especialista em Saúde Pública e Especialista em Saúde da Família e Comunidade. Professora Substituta na \\ Universidade Federal de Pelotas (UFPEL). \\ c Fisioterapeuta. Pós-Graduada em Traumato-Ortopedia, Especialista em Informação e Tecnologia em Saúde, Mestranda em Ciências da Saúde pela FURG.
}

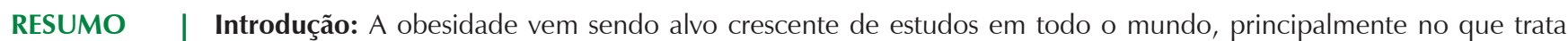
sobre a obesidade infantil.

Objetivos: Contribuir para uma melhor compreensão a respeito do vínculo entre mãe e filho na adesão ao tratamento da obesidade infantil.

Materiais e Métodos: Foram entrevistadas sete mães de crianças obesas, todas usuárias do Ambulatório de Nutrição, localizado no sul do Rio Grande do Sul. Os dados foram coletados através de entrevistas semiestruturadas e o material foi submetido a análise de conteúdo.

Resultados: Após análise e categorização dos dados provenientes das entrevistas foram identificados três eixos temáticos, a saber: 1) cuidados com a criança; 2) trajetória dos vínculos e 3) dificuldade de a mãe perceber o peso da criança. Esses eixos nortearam a discussão sobre a atenção à saúde da criança com excesso de peso neste estudo. Foi demonstrado que a ligação materna influencia negativamente sobre a adesão, já que não há uma única forma de estabelecer essa relação. Pode ser visto que, embora não haja uma única forma de estabelecer o vínculo materno, teve uma influência negativa sobre a adesão ao tratamento.

Conclusão: No final do estudo, pode-se perceber que o vínculo materno influencia na adesão ao tratamento, mas, não há uma maneira simples para estabelecer esta ligação, por conseguinte, não há um tratamento mais eficiente ou mais correto, este dependerá de cada paciente e como mãe e filho interagem diante de situações.

Palavras-chave: criança; obesidade; tratamento.

\section{ABSTRACT}

\begin{abstract}
Introduction: Obesity has been increasing focus of studies around the world, especially when it deals with childhood obesity.
Objectives: To contribute to a better understanding about the bond between mother and child in the treatment adherence of childhood obesity.
\end{abstract}

Materials and Methods: Seven mothers of obese children were interviewed. They were all users of the Nutrition Clinic, located in southern Rio Grande do Sul. Data were collected through semi-structured interviews and the material was subjected to content analysis.

Results: After analysis and categorization of data from interviews, three thematic areas were identified: 1) child care; 2) trajectory of bonds and 3) mother's difficulty to realize the weight of the child. These thematic areas guided the discussion about health care for overweight children in this study. It was shown that the maternal link negatively influences on compliance, since there is no single form of establishing this relationship. It can be seen that although there is no single form of establishing the maternal bond, it had a negative influence on treatment compliance.

Conclusion: At the end of the study, can be seen that the maternal bond influences the adherence to treatment, but there is no single way to establish this connection, therefore, there is no more efficient or more correct treatment, it will depend on each patient and how the pair, mother and son, interact face of situations.

Keywords: child; obesity; treatment. 


\section{INTRODUÇÃO}

O tema obesidade vem sendo alvo crescente de estudos em todo o mundo, principalmente no que trata sobre a obesidade infantil. A obesidade pode ser definida, de forma simplificada, como uma doença caracterizada pelo acumulo excessivo de gordura corporal, sendo consequência do balanço energético positivo e que acarreta repercussões à saúde, com perda importante na qualidade e no tempo de vida ${ }^{1}$. O Peso e Estatura são preconizados pelo Ministério da Saúde (MS) e pela Organização Mundial da Saúde (OMS), utilizando a referência internacional do National Center for Health Statistics (1977), classificando a condição nutricional por meio do índice de massa corporal $\left(\mathrm{IMC}=\right.$ peso $\left[\mathrm{kg} / / \text { estatura }^{2}[\mathrm{~m}]\right)^{2}$. A Sociedade Brasileira de Pediatria adota que para as crianças maiores de 5 anos, o peso excessivo (sobrepeso) está relacionado a valores entre os percentis 85 e 97; já a obesidade está relacionada a valores entre os percentis 97 e 99,9 e a obesidade grave a valores acima do percentil 99, $9^{3}$.

Segundo a OMS, a obesidade é a epidemia do século XXI e estima-se que atinja cerca de $50 \%$ da população mundial até $2025^{2}$, sendo que a obesidade infantil já é a doença pediátrica mais prevalente em nível mundial e constitui um dos mais graves problemas de saúde pública no mundo. Os números são claros: a cada ano surgem mais 400.000 novos casos, somando-se aos 45 milhões de casos já existentes de crianças com excesso de peso ${ }^{4}$.

Desta forma, a obesidade infantil deve ser pensada e tratada como questão relevante do ponto de vista da saúde pública. Além disto, sua possível relação com o vínculo materno-infantil merece atenção já que é sabido que a alimentação ocupa papel importante na díade mãe-filho, pois, além de ser uma maneira de manter o indivíduo vivo e aplacar a fome, o ato de comer é um meio de troca de afeto, comunicação, interação e por vezes, também de oposição ${ }^{5}$.

Bowlby ${ }^{6}$ aborda em seu estudo a questão do vínculo materno, e que este se dá por uma ligação composta por uma rede de comportamentos, que tem relação com a proteção natural da espécie, no sentido de que ao nascer, o bebê é pequeno e indefeso, sendo difícil sua sobrevivência sem a proteção de um cuidador. Para o autor, o vínculo pode ser definido como adequado, fraco ou ausente. Observa-se que a manutenção dessa proximidade não é passiva na criança, tendo em vista que a partir de certa idade ela também passa a procurar ativamente a proximidade da mãe, desde segui-la até mesmo gesticular efusivamente. A criança também busca a interação. Assim, ela não só demonstra atividade ao chamar a atenção da mãe, como também se mostra disponível e responsiva aos estímulos dela, cada um contribuindo com sua parte ${ }^{6}$.
Para a OMS, algumas mães apresentam a preocupação em alimentar seu bebê, o que é muito comum. Este sentimento inicia-se ainda no período da gestação, permanecendo após o nascimento e estendendo-se ao longo da primeira infância. Podendo ser justificado que a alimentação esta muito interligada com o sinônimo de saúde. A relação mãebebê se torna base para a saúde mental de todo o indivíduo, tendo em vista que esta seria moldada na primeira infância pela mãe através de todos os contextos que ela consegue proporcionar ao seu filho ${ }^{7}$. Desta forma, torna-se importante considerar os sentimentos da mãe durante a gestação, o parto e puerpério, já que este vínculo se perpetuará e influenciará ao longo da vida da criança.

As primeiras relações desenvolvidas entre a mãe e o bebê vêm sendo discutidas ao longo do tempo por teóricos importantes. Freud descreveu como o primeiro estágio do Desenvolvimento Psicossexual a fase oral. Nesta fase, o prazer sexual, predominantemente estaria relacionado à excitação da cavidade oral e dos lábios, portanto à alimentação. A pulsão do bebê nesta fase, segundo este ponto de vista, é o de receber o alimento e a boca é a primeira área do corpo que ele consegue controlar. Porém Freud não se deteve a ampliar este tema, no sentido de destacar o papel importante encenado por possíveis alterações vivenciadas nesta primeira relação ${ }^{8}$.

Acredita-se, portanto, que estender o olhar sobre a vinculação materno-infantil e as peculiaridades dos sistemas familiares nos quais a díade mãe/criança está imersa poderá ser útil para a criação de estratégias que beneficiem a adesão ao tratamento nutricional da criança que se encontra obesa. O presente estudo tem como objetivo contribuir para uma melhor compreensão a respeito do vínculo entre mãe e filho na adesão ao tratamento da obesidade infantil.

\section{MATERIAIS E MÉTODOS}

Neste estudo utilizou-se a abordagem qualitativa ${ }^{9}$, tendo em vista que pesquisava-se as representações sociais e aspectos comportamentais que envolvem a relação entre mães e filhos com diagnóstico de obesidade. Foram entrevistadas sete mulheres adultas, mães de sete crianças entre sete e nove anos, de ambos os sexos, que possuíam, conforme o MS e a OMS, diagnóstico de obesidade de acordo com o IMC. Tais crianças consultavam no Ambulatório de Nutrição, de um Município localizado no sul do Rio Grande do Sul. Estas crianças também pertenciam ao Grupo de Controle a Obesidade onde ocorria a verificação do IMC e promoção de saúde, desta forma mantendo IMC atualizado. A escolha das participantes se deu por conveniência.

Para buscar resultados subjetivos quanto à influência da mãe na obesidade dos filhos foi utilizada entrevista 
semiestruturada composta por 46 questões norteadoras referentes ao tema da pesquisa, envolvendo gestação, parto/ primeiros cuidados com o bebê, saúde da mãe/saúde da criança, alimentação e experiência da maternidade. Tais questões nortearam a análise dos dados.

Foram respeitados todos os princípios éticos estabelecidos pelo Conselho Nacional de Saúde na Resolução № 466 de 12 de dezembro de 2012. O parecer do Comitê de Ética encontra-se consubstanciado sob o número 354.591, aprovado em 02 de setembro de 2013. As mães atendidas receberam esclarecimentos sobre os objetivos e procedimentos que foram adotados nesta pesquisa e assinaram um Termo de Consentimento Livre e Esclarecido, concordando em participar da pesquisa.

As entrevistas foram realizadas no Ambulatório de Especialidades do Hospital Escola da referida cidade, durante os meses de setembro a dezembro de 2013, numa sala climatizada com isolamento acústico para uma maior privacidade e comodidade das entrevistadas. Estas entrevistas foram feitas individualmente, efetuando-se uma por dia, com duração de aproximadamente uma hora. Optou-se por nomes fictícios para preservar a identidade dos participantes e foi utilizado um gravador, com a autorização das entrevistadas. Tendo em vista que a gravação e posterior transcrição permitiram uma análise integral dos dados.

Os resultados foram transcritos e analisados de acordo com a técnica da análise de conteúdo temática conforme Bardin e Minayo, compreendendo três etapas: primeiramente a préanálise, logo após a exploração do material e em seguida o tratamento dos resultados e interpretação. Durante a préanálise ocorreu a organização e sistematização das ideias. Na exploração do material, os temas a serem trabalhados foram identificados. Por fim, na interpretação dos resultados, os dados obtidos durante as entrevistas foram analisadas com base nos autores referenciados ${ }^{9,10}$.

\section{RESULTADOS E DISCUSSÃO}

Observou-se, durante os trabalhos realizados, forte influência negativa da relação entre mãe e filho na obesidade infantil. Por isso, optou-se em averiguar sobre a importância do vínculo desta díade na adesão ao tratamento nutricional. Sendo assim o resultado da pesquisa se deu da seguinte forma:

\section{Um recorte da situação familiar}

1) Joana, estudante de nível superior, educadora infantil, solteira, mãe de Miguel. Miguel tem oito anos, mora com a mãe, os avós maternos e a tia; 2) Débora, possui curso técnico, dona de casa, casada, mãe de Camila. Camila tem nove anos, mora com os pais; 3) Maria, estudante de nível superior, funcionária pública, casada, mãe de Hanna. Hanna tem nove anos, mora com os pais, porém a avó e a tia materna moram em uma casa nos fundos. Enquanto os pais trabalham, a tia cuida da menina; 4) Rebeca, ensino médio completo, auxiliar administrativo, separada, mãe de Vanessa. Vanessa tem oito anos, mora com a mãe, mas a avó materna se desloca todas as manhãs para cuidá-la; 5) Eva, ensino médio incompleto, doméstica, separada, é mãe de Luan e de João. Luan tem sete anos, mora com a mãe e o irmão. A tia de Eva passa as manhãs com Luan, enquanto a mãe trabalha; 6) Mara, ensino médio completo, comerciária, mãe de Jéssica. Jéssica tem nove anos, mora com a mãe e fica as manhãs na casa da avó, já que a mãe está trabalhando; 7) Bianca, ensino médio completo, dona de casa, casada, mãe de Eduardo e Emily. Eduardo tem nove anos, mora com a mãe e o padrasto. Desde que Bianca ganhou Emily e a bebê ficou internada na UTI, Eduardo está na casa da avó materna.

Conforme as entrevistas realizadas, foram identificados os seguintes eixos temáticos: 1) cuidados com a criança; 2) trajetória dos vínculos e 3) dificuldade da mãe em perceber o peso da criança.

\section{Cuidados com a criança}

A mãe sempre irá nomear as sensações do bebê, sendo estas prazerosas ou não. Portanto, a mãe irá ofertar o quê o bebê necessita desta forma não permitindo que ele vivencie o sentimento de frustração, já que não lhe é permitido chorar. Dentre as rotinas, com a alimentação não é diferente, o seio e a mamadeira são ofertados muitas vezes sem o bebê sentir fome, causando um momento prazeroso que estará associado ao ato de alimentar-se ${ }^{5}$.

Os problemas emocionais estariam vinculados a relação mãe-bebê, já que a estruturação psíquica do indivíduo seria moldada já na primeira infância e é neste momento que a mãe possui maior influência sobre o filho, pois existe uma necessidade e dependência absoluta por parte deste ${ }^{11}$. Segundo Winnicott ${ }^{11}$, os bebês apresentam-se de modos diferentes e precisam que as mães estejam identificadas para uma melhor compreensão de suas necessidades, sendo uma delas a amamentação. Neste contexto é importante estar atento ao que envolve este processo, pausas entre as mamadas, a maneira como segurá-lo, o toque, não apenas alimentá-lo. Conhecendo e respeitando estas individualidades, o bebê não se sentirá invadido, porém o inverso fará com que ele adquira sentimentos negativos que poderão ficar armazenados na memória.

$\mathrm{Na}$ fala de Maria evidencia-se maior tempo destinado ao trabalho do que aos cuidados com a criança. A quantidade menor deste tempo dedicado a filha parece influenciar 
no convívio entre ambas e também na maneira como é conduzida a alimentação, tornando o regramento e a rotina, mais difíceis.

"Agora a gente tem mais tempo. E essa obesidade da Hanna partiu disso porque não tinha hora pra come. A hora que ficava pronta, ela comia. (...) antes era a hora que a gente chegava, a hora que alguém ia fazer alguma coisa, porque a gente trabalhava muito e chegava tarde. Às vezes ela tava comendo e dormindo na mesa, por isso que ela ficou com o peso que ela tá, de comer, de não ter hora, de ficar com muita fome. Aí não come, espera a janta, chegava na janta comia dois pratos bem grande, ela sempre foi boa." (Maria, mãe da Hanna, 9 anos)

Já no relato de Bianca observa-se a necessidade de ser aceita como igual em um grupo, não levando em conta seu estado gestacional e os prejuízos que este pode acarretar ao seu bebê. Para ser aceito pelo grupo de iguais, o jovem poderá sentir-se pressionado a ter o mesmo comportamento do grupo utilizando substâncias psicoativas, o que acaba por expô-lo a muitos comportamentos de risco ${ }^{12}$.

"Eu nunca fui viciada. Eu fumava porque meus amigos fumavam. Ele fumava. (...) Sempre foi assim. Até pra cigarro. Eu fumei 14 anos e parei agora nesta gestação. Parei! Na do Eduardo não! Dele não!" (Bianca, mãe de Eduardo, 9 anos)

Fica demonstrado nestas falas que a movimentação da mãe em relação a leitura das necessidades do seu filho, nem sempre ocorre da forma como se espera. Hábitos anteriores a maternidade tanto de saúde como de trabalho, não são modificados, assim a rotina que deveria oferecer estabilidade ao bebê, acaba não ocorrendo.

\section{Trajetória dos vínculos}

A construção do papel materno é um processo cognitivoafetivo complexo, que tem suas origens na própria experiência da mãe enquanto filha e gradualmente é vivenciado ao longo da gestação, sendo construído e modificado ao longo das interações com o filho. Nestas vivências a criança desempenha um importante papel, pois tende a regular os comportamentos maternos a partir de suas respostas, onde o desenvolvimento do apego é uma experiência profunda que requer contato físico constante ${ }^{13}$.

No relato de Joana aparece a dificuldade de se vincular com o filho, pois não consegue se perceber no papel de mãe.

“Era muito difícil. Até porque eu tive ele, mas eu não aceitava que eu era mãe dele. Eu brincava com ele, assim, mas era muito pouco. (...) eu não conseguia me ver como mãe dele sabe. Acho que até como irmã. Alguma coisa assim. Até pouco tempo eu não conseguia chamar ele de filho. Eu comecei a chamar ele de filho há pouco tempo, chamava ele só de Miguel." (Joana, mãe de Miguel, 8 anos)

Já para Débora, há uma dificuldade de se ver como mãe, não diferenciando-se do marido. Seu discurso é sempre relacionado ao sentimento do casal.

\begin{abstract}
"Teve uma época que ela - a filha - foi pra minha mãe de férias, ficou uma semana lá. Nós - ela e o marido - chorávamos, nunca tínhamos ficado longe dela, os dois choravam. Ligava pra ela, nós dois chorava. (...) e nós chorando do lado. Claro ela tava brincando com as primas, nem... né? Ah, não Camila tu nunca mais vai ficar longe tanto tempo assim. E nunca mais foi (risos)." (Débora, mãe de Camila, 9 anos)
\end{abstract}

Para Mara a separação conjugal foi algo conflituoso, onde esta acabou transferindo sua angustia para a filha e transformando assim, em apego exagerado. Desta forma mãe e filha tornam-se dependentes uma da outra.

\begin{abstract}
“Era uma tragédia anunciada né? Então eu passei muito tempo da gravidez chorando, tinha contrações na volta do umbigo de tanto chorar as vezes. (...) Milha filha seria outra pessoa se eu tivesse criado ela com marido dentro de casa. (...) pra tirar o mama eu nunca fiquei tão doente fisicamente, eu tive uma febre horrorosa, doía todo o meu corpo, não tinha parte do meu corpo que não doesse. Fiquei de cama toda errada. Como doeu! (...) Quando eu boto na cama dela, ela pega no sono, eu volto pra minha, daqui a pouco ela tá lá de novo: "Ai mãe eu preciso ficar contigo, eu não to conseguindo dormir!" (Mara, mãe de Jéssica, 9 anos)
\end{abstract}

O modelo de mãe intrusiva, aquela que não respeita os tempos e os desejos da criança, portanto não sendo sensível as necessidades ligadas ao desenvolvimento infantil, onde o uso do poder se sobrepõe ao do amor, seja por ansiedade materna, superproteção ou autoimagem narcísica projetada na criança. Esses comportamentos, associados a um desmame tardio, reforçam a interpretação de que a mãe invade o mundo interno do filho e a criança passa a ocupar o espaço externo, pela obesidade ${ }^{14}$.

Embora Vanessa já estivesse com 3 anos, Rebeca não conseguia parar de dar de mamar. Precisou da intervenção do pai de Vanessa para que isto acontecesse. Rebeca não consegue perceber sua dificuldade, deslocando para a filha o comportamento de apego. Esse quadro se associa também a um aumento de dependência que parece ser alimentada pela mãe e pela própria criança. 
"Porque eu chegava, ela pedia direto, eu quero tetê, eu quero tetê. E eu ficava com pena de não dar, eu passava o dia inteiro longe, e eu dava teta pra ela. E um dia nós fomos num aniversário e ela já tava grande e baixou a minha blusa, e ele disse a partir de hoje tu não vai mais tomar, ralhô com ela e ela começou a chorar né? (...) Tu sabe que até hoje eu durmo com ela e ela diz eu sinto uma saudade do tetê. Ela diz pra mim. Eu acho que é uma segurança que ela tem." (Rebeca, mãe de Vanessa, 8 anos)

A família tem papel regulador e um dos movimentos importantes é encontrar o equilíbrio entre o processo de individualização de cada um de seus membros e a necessidade de que isso seja mútuo para que o desenvolvimento do grupo possa ocorrer. A autora ainda relata que famílias com diálogos raros, não evidenciam sintonia em nível de comunicação, o que acaba por gerar dúvida, insegurança e algum membro da família poderá desenvolver transtorno alimentar $^{15}$.

Joana refere a dificuldade que encontrou durante a gestação devido a não ter o apoio do pai. Desde a descoberta que a filha estava grávida até o nascimento de Miguel, o pai de Joana não falou mais com ela.

"Eu sempre fui muito ligada ao meu pai! Eu senti muito essa falta, assim sabe, de falar com ele." (Joana, mãe de Miguel, 8 anos)

\section{Dificuldade da mãe em perceber o peso da criança}

Na infância e na adolescência, um dos motivos que poderá levar ao negligenciamento do peso pelos pais e pelos educadores é a falsa crença que o crescimento por si só resolve o problema ${ }^{16}$. Débora apesar de levar a filha ao Grupo de Obesidade possui uma imagem corpórea distorcida da filha e dos demais participantes do grupo.

\footnotetext{
"Até no grupo eu não achei ninguém, assim sabe óhhh! Tinha crianças assim, que eu olhei e não achei que fosse, porque comparadas tinha mais magrinha do que ela, que aos meus olhos não tinha necessidade de tá né? (...) O guri é bem magrinho, magrinho até demais. Ai quando ela viu a Camila, foi que ela viu que a guria tava bem... quando ela viu a Camila, ela disse Camila como tu tá magrinha." (Débora, mãe de Camila, 9 anos)
}

Eva verbaliza o seu sentimento negativo frente a obesidade do filho, demonstra o quando faz para ajudá-lo e justifica que com o crescimento o filho está e irá emagrecer:
"Aí eu me sinto mal né? Quando dizem que ele tá obeso. Porque eu cuido, ele come na hora, eu converso com ele... Eu aproveito esse momento de... de nutrição. E ele tá crescendo... quando cresce emagrece." (Eva, mãe de Luan, 7 anos)

\section{CONSIDERAÇÕES FINAIS}

A obesidade infantil pode representar dificuldades afetivas na relação mãe-filho, sendo essa dificuldade manifestada através do corpo, o que chamamos de somatização, ou seja, o corpo é utilizado como forma de queixa e sintomas físicos.

É de extrema importância que, no tratamento dietoterápico, o profissional nutricionista saiba como a mãe está emocionalmente, qual seu entendimento sobre seus próprios sentimentos, os de seu filho e como eles estão interligados, qual a sua compreensão frente ao tratamento nutricional, bem como suas limitações em todos os contextos, sejam elas econômicas, sociais ou intelectuais, já que todos estes itens citados podem influenciar na adesão ao tratamento.

Diante destes inúmeros sentimentos e limitações que permeiam a obesidade, torna-se difícil para a mãe compreender que a adesão ao tratamento nutricional não é apenas levar o filho na consulta e restringir a alimentação, mas que é um processo, sendo necessário compreender os sentimentos que o envolve.

Através do estudo e apoiado no referencial teórico podemos dizer que o vínculo materno influencia na adesão ao tratamento, porém não existe uma forma única deste vínculo se estabelecer, já que, cada díade é única e cada indivíduo singular. Sendo o vínculo satisfatório para a dupla, a internalização desta experiência é positiva, do contrário e dependendo de como se encontra cada dupla, este vínculo pode se estabelecer de forma disfuncional, sendo a experiência negativa.

Desta forma também não existe um tratamento mais eficiente ou mais correto, a eficácia irá depender de cada paciente. Porém não nos cabe em momento algum julgar as mães pela obesidade de seus filhos, mas sim entender este fenômeno, acolhê-las e trazê-las para a responsabilidade e participação, tornando-as facilitadoras no tratamento.

\section{REFERÊNCIAS}

1. Tavares T. Obesidade e qualidade de vida: revisão da literatura. Rev Méd Minas Gerais. 2010;20(3):359-66.

2. Ministério da Saúde (BR). Secretaria de Atenção à Saúde. Cadernos de Atenção Básica. Diabetes Mellitus. Brasília: Ministério da Saúde; 2006

3. Sociedade Brasileira de Pediatria. Obesidade na infância e adolescência: manual de orientação. São Paulo: SBP; 2012. 
4. Setzer V. Efeitos negativos dos meios eletrônicos em crianças, adolescentes e adultos [Internet]. 2012 [cited 2016]. Available from: http://www.ime.usp.br/ vwsetzer/efeitos-negativos-meios.html

5. Moraes P, Dias C. Nem só de pão de vive: a voz das mães na obesidade infantil. Psicol Ciênc Prof. 2013;33(1):46-59. http:// dx.doi.org/10.1590/S1414-98932013000100005

6. Bowlby J. Apego e perda: separação, angustia e raiva. 3a ed. São Paulo: Martins Fontes; 2004.

7. Brenner C. Noções básicas de psicanálise: introdução à psicologia psicanalítica. Rio de Janeiro: Editora Imago; 1987.

8. Weber L, Prado P, Viezzer A, Brandenburg O. Identificação de estilos parentais: o ponto de vista dos pais e dos filhos. Psicol Reflex Crít. 2004;17(3):323-31. http://dx.doi.org/10.1590/S010279722004000300005

9. Minayo M. O desafio do conhecimento: pesquisa qualitativa em saúde. 11aㅡ ed. São Paulo: Hucitec; 2000.

10. Bardin L. Análise de conteúdo. Lisboa: Edições 70; 1979.
11. Winnicott D. Os bebês e suas mães. 4a ed. São Paulo: Martins Fontes; 2013.

12. Wagner $M$, Oliveira M. Habilidades sociais e abuso de drogas em adolescentes. Psicol Clín. 2007;19(2):101-16. http://dx.doi. org/10.1590/s0103-56652007000200008

13. Carmona E, Coca K, Vale I, Abrão A. Conflito no desempenho do papel de mãe em estudos com mães de recém-nascidos hospitalizados: revisão integrativa. Rev Esc Enferm USP. 2012; 46(2):505-12. http://dx.doi.org/10.1590/S0080-62342012000 200032

14. Santos L, Rabinovich E. Situações familiares na obesidade exógena infantil do filho único. Saúde Soc. 2011;20(2):507-21. http://dx.doi. org/10.1590/S0104-12902011000200021

15. Spada P. Obesidade infantil: aspectos emocionais e vínculo mãe/ filho. Rio de Janeiro: Editora Revinter; 2005.

16. Parizkavá J, Hills A. Childhood obesity: prevention and treatment. Florida: CRC Press; 2005. 